Editorial

\title{
Volume 3: SGAMR is Always on Track!
}

\author{
${ }^{1}$ Chiara Bedon, ${ }^{2}$ Mario D'Aniello and ${ }^{3}$ Flavio Stochino \\ ${ }^{1}$ Department of Engineering and Architecture, University of Trieste, Trieste, Italy \\ ${ }^{2}$ Department of Structural Engineering, University of Naples Federico II, Naples, Italy \\ ${ }^{3}$ Department of Civil, Environmental and Architectural Engineering, University of Cagliari, Cagliari, Italy
}

The year 2019 represents a new growing step for SGAMR, that starts to publish "continuously" all the accepted papers, once they are subjected to positive, blinded peer-review process. This is a further effort to improve the service for the contributors and for the readers, given that the efficiency of the journal to share knowledge can be maximized.

Hänig et al. (2019) focus on the experimental analysis and optimized modelling in support of the design of laminated glass members characterized by various types of interlayers. Sable et al. (2019) also investigate the bending response of laminated glass members with different bonding layers, with a focus both on the precracked and post-cracked performance assessment.

The mechanical characterization and analysis of glass members is a key aspect for the civil engineering applications, but for the constructional sector in general. In this regard, (Joshi and Webb, 2019) discuss about the mechanical analysis of thin glass panels for photovoltaics applications. Last but not least, another relevant contribution on the mechanical performance assessment comes from (Chordiya and Goel, 2019), with a focus on the drop weight impact response of tubes that are filled by polymeric syntactic foam.

For the same Volume, a number of contributions is focused on the chemical and physical analysis of various relevant aspects for glass and glass-related applications. Cheng-Yu et al. (2019) present a new golden red glass that is based on $\mathrm{Na}_{2} \mathrm{O}-\mathrm{CaO}-\mathrm{SiO}_{2}$ system, without $\mathrm{SnO}_{2}$ and $\mathrm{PbO}$. The benefits of using new golden red sodium calcium silicate glasses are proved at several levels, like the reduction of gold amount, the minimized cost and the reduced pollution to the environment. Rao (2019) describes original experimental studies aimed at investigating the structure of lead vanadate glasses. A focus is given to the structural role of $\mathrm{GeO}_{2}$ in $(50-\mathrm{x})$ $\mathrm{PbO}$, with an extended discussion of original experimental observations.

Two further original contributions come from (Owoyemi et al., 2019; Gomaa et al. 2019a; 2019b). First, the attention is focused on the analysis of the total conductivity of calcium iron borate glasses. Later on, a deep discussion is provided on the effects of acid frosting on the actual microstructure and mechanical strength of eroded soda-lime-silica glasses, as an effect of sandstorm.
Finally, SGAMR moves with (Azzawi et al., 2019) towards the definition and design optimization of a novel system able to measure the ammonia gas pressure in the infrared region. The paper presents some first measurements based on the spectral analyzer (with a focus on the 1.5 um region). Successively, the sensing system of gases is proposed. As shown, the advantages of the sensor system are high accuracy and easy application in laboratory or industrial scenarios.

As usual, a special thanks to all the authors and reviewers! Enjoy this volume!

The Editor in Chief and the Associate Editors

\section{References}

Azzawi, M. M., Hussein, M. J., Jebur, N. K. \& Saad, H. F. (2019). Design and Construction of Optical System to Detect of Ammonia Gas. International Journal of Structural Glass and Advanced Materials Research, 3(1), 56-61.

Cheng-Yu, W., Nuan-Xin, W., Yi, G., Hua-Juan, T. \& W, W. P. (2019). New Golden Red Sodium Calcium Silicate Glasses. International Journal of Structural Glass and Advanced Materials Research, $3(1), 15-20$.

Chordiya, Y. M. \& Goel, M. D. (2019). Drop Weight Impact Behaviour of Tube Filled Polymeric Syntactic Foam. International Journal of Structural Glass and Advanced Materials Research, 3(1), 40-55.

Gomaa, H. M., Elkatlawy, S. M. \& El-Dosokey, A. H. (2019a). Total Conductivity of Calcium Iron Borate Glasses Using an Empirical Formula. International Journal of Structural Glass and Advanced Materials Research, 3(1), 34-39.

Gomaa, H. M., Elkatlawy, S. M. \& El-Dosokey, A. H. (2019b). Effect of Niobium Oxide Incorporation on Optical Properties of Sodium Bismuth Borate Glasses. International Journal of Structural Glass and Advanced Materials Research, 3(1), 79-86.

Hänig, J., Bukieda, P., Engelmann, M., Stelzer, I. \& Weller, B. (2019). Examination of Laminated Glass with Stiff Interlayers - Numerical and Experimental Research. International Journal of Structural Glass and Advanced Materials Research, 3(1), 1-14. 
Joshi, D. \& Webb, J. E. (2019). Mechanical Reliability Calculations for the Thin Specialty Glass PV Solar Panels. International Journal of Structural Glass and Advanced Materials Research, 3(1), 87-97.

Owoyemi, A. G., Matthew, G. O. \& Owoeye, S. S. (2019). Influence of Acid Frosting on the Microstructure Characteristics and Mechanical Strength of Eroded Soda-Lime-Silica Glasses by Sandstorm. International Journal of Structural Glass and Advanced Materials Research, 3(1), 28-33.
Rao, P. T. (2019). ESR and FT-IR Studies on GeO2 Substituted Lead Vanadate Semiconducting Glass System. International Journal of Structural Glass and Advanced Materials Research, 3(1), 21-27.

Sable, L., Kinsella, D. \& Kozłowski, M. (2019). Influence of EVA, PVB and Ionoplast Interlayers on the Structural Behaviour and Fracture Pattern of Laminated Glass. International Journal of Structural Glass and Advanced Materials Research, 3(1), 62-78. 